\title{
Effect of plateau pika disturbance and patchiness on ecosystem carbon emissions in alpine meadow in the northeastern part of Qinghai-Tibetan Plateau
}

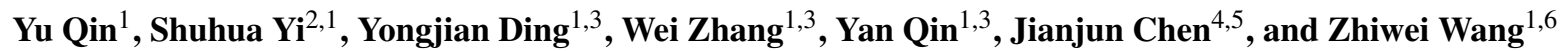 \\ ${ }^{1}$ State Key Laboratory of Cryospheric Sciences, Northwest Institute of Eco-Environment and Resources, \\ Chinese Academy of Sciences, 320 Donggang West Road, Lanzhou, 730000, China \\ ${ }^{2}$ School of Geographic Sciences, Nantong University, 999 Tongjing Road, Nantong, Jiangsu, 226007, China \\ ${ }^{3}$ University of the Chinese Academy of Sciences, no. 19A Yuquan Road, Beijing, 100049, China \\ ${ }^{4}$ College of Geomatics and Geoinformation, Guilin University of Technology, 12 Jiangan Road, Guilin, 541004, China \\ ${ }^{5}$ Guangxi Key Laboratory of Spatial Information and Geomatics, 12 Jiangan Road, Guilin, 541004, China \\ ${ }^{6}$ Guizhou Institute of Prataculture, Guizhou Academy of Agricultural Sciences, Guiyang, 550006, China
}

Correspondence: Shuhua Yi (yis@ntu.edu.cn)

Received: 21 June 2018 - Discussion started: 20 July 2018

Revised: 7 March 2019 - Accepted: 11 March 2019 - Published: 19 March 2019

\begin{abstract}
Plateau pika (Ochotona curzoniae) disturbance and patchiness intensify the spatial heterogeneous distribution of vegetation productivity and soil physicochemical properties, which may alter the ecosystem carbon emission process. Nevertheless, previous research has mostly focused on the homogeneous vegetation patches rather than heterogeneous land surface. Thus, this study aims to improve our understanding of the difference in ecosystem respiration $(\mathrm{Re})$ over heterogeneous land surface in an alpine meadow grassland. Six different land surface types, namely large bald patches, medium bald patches, small bald patches, intact grassland, above pika tunnel and pika pile, were selected to analyze the response of Re to pika disturbance and patchiness and the key controlling factors. The results showed that (1) Re in intact grassland was 0.22-1.07 times higher than pika pile and bald patches, (2) soil moisture (SM) of intact grassland was $2 \%-11 \%$ higher than that of pika pile and bald patches, despite the fact that pika disturbance increased the water infiltration rate while soil temperature (ST) in intact grassland was $1-3^{\circ}$ less than pika pile and bald patches, (3) soil organic carbon (SOC) and total nitrogen (TN) in intact grassland were approximately $50 \%$ and $60 \%$ less than above pika tunnel, whereas they were $10 \%-30 \%$ and $22 \%-$ $110 \%$ higher than pika pile and bald patches, and (4) Re was significantly correlated with SM, TN and vegetation biomass $(P<0.05)$. Our results suggested that pika disturbance and
\end{abstract}

patchiness altered the ecosystem carbon emission pattern, which was mainly attributed to the reduction in soil water and supply of substrates. Given the wide distribution of pikas and the large area of bald patches, the varied Re in heterogeneous land surfaces should not be neglected in the estimation of ecosystem carbon emissions at the plot or regional scale.

\section{Introduction}

Ecosystem respiration ( $\mathrm{Re}$ ) is the key process for determining the carbon budget in the terrestrial ecosystem. Thus, even small imbalances between $\mathrm{CO}_{2}$ uptake via photosynthesis and $\mathrm{CO}_{2}$ release by ecosystem respiration can lead to significant interannual variation in atmospheric $\mathrm{CO}_{2}$ (Schimel et al., 2001; Cox et al., 2000; Grogan and Jonasson, 2005; Oberbauer et al., 2007; Warren and Taranto, 2011). Dependent on autotrophic (plant) and heterotrophic (microbe) activity, ecosystem respiration is mainly controlled by abiotic factors (primarily temperature and water availability; Chimner and Welker, 2005; Flanagan and Johnson, 2005; Nakano et al., 2008; von Buttlar et al., 2018) and the supply of carbohydrate fixed by leaves, vegetation litter and soil organic matter (Janssens et al., 2001; Reichstein et al., 2002). Therefore, any external disturbance altering environmental conditions 
and affecting vegetation growth exerts profound influence on ecosystem carbon emission.

One of the basic functions of terrestrial ecosystem is to regulate the carbon balance between the atmosphere and ecosystem (Canadell et al., 2007; Le Quéré et al., 2014; Ahlström et al., 2015). However, this balance could be broken by widespread land degradation (Post and Kwon, 2000; Dregne, 2002), which accompanied the reduction in photosynthetic fixed carbon dioxide from the atmosphere and carbon sequestration by soils (Defries et al., 1999; Upadhyay et al., 2005). It was estimated that land degradation has resulted in 19-29 Pg C loss worldwide (Lal, 2001). Over the past decades, grasslands have experienced patchiness throughout the world, and this process is still ongoing (Baldi et al., 2006; Wang et al., 2009; Roch and Jaeger, 2014). Patchiness generally refers to a landscape that consists of remnant areas of native vegetation surrounded by a more heterogeneous and patchy situation (Kouki and Löfman, 1998). Other than climate change (Yi et al., 2014), vegetation self-organization (Rietkerk et al., 2004; Venegas et al., 2005; McKey et al., 2010) or anthropogenic disturbances (Kouki and Löfman, 1998; Yi et al., 2016), rodent burrowing activities were also considered to be the origin of the patchiness (Wei et al., 2006; Davidson and Lightfoot, 2008). This patchiness intensified spatial heterogeneity of the land surface and led to the changing of the structure and function of the original ecosystem (Herkert et al., 2003; Bestelmeyer et al., 2006; Lindenmayer and Fischer, 2013). For instance, there is abundant evidence that patchiness not only intensified the spatial heterogeneous distribution of ecosystem organic carbon (C) and vegetation productivity (Yan et al., 2016; Qin et al., 2018) but also altered the pattern of coupled water and heat cycling between the land surface and the atmosphere (Saunders et al., 1991; You et al., 2017; Ma et al., 2018). Consequently, this may alter the ecosystem carbon emission process (Juszczak et al., 2013).

Plateau pikas (Ochotona curzoniae, hereafter pikas) are small mammals endemic to the alpine grasslands of the Qinghai-Tibetan Plateau (QTP; Smith and Foggin, 1999; Lai and Smith, 2003). Living underground, they excavated deep layers of soil to the surface through foraging and digging activities (Lai and Smith, 2003) and led to substantial bald piles on the ground. The bald pile was considered to gradually become bald patches under soil erosion, gravity, freezethaw and other factors (Chen et al., 2017; Ma et al., 2018). As a consequence, natural vegetation patches and adjacent bald patches with different sizes and pika piles represent the most common landscape pattern in the alpine meadow grassland on the QTP. Previous studies have demonstrated that pika disturbance and patchiness weaken the function of alpine meadow as a carbon sink (Liu et al., 2013; Peng et al., 2015; Qin et al., 2018) and accelerated the ecosystem carbon emission rate (Qin et al., 2015a). Nevertheless, most of these studies have mainly focused on ecosystem carbon emission rate under the homogeneous land surface rather than hetero- geneous land surfaces. Thus, the specific aims of this study were to (1) investigate the spatial heterogeneity of Re among different surface types (plateau pika pile, above pika tunnel, and different sizes of bald patches and vegetation) of alpine grassland and to (2) illuminate the potential regulating mechanism of pika disturbance and patchiness to ecosystem respiration $(\mathrm{Re})$ in an alpine meadow grassland in the northeastern part of Qinghai-Tibetan Plateau (QTP).

\section{Materials and methods}

\subsection{Site description}

This study was conducted at the permanent plots at the Suli Alpine Meadow Ecosystem Observation and Experiment Station $\left(98^{\circ} 18^{\prime} 33.2^{\prime \prime}, 38^{\circ} 25^{\prime} 13.5^{\prime \prime}\right.$; 3887 m a.s.l.; Northwest Institute of Eco-Environment and Resources, Chinese Academy of Sciences). The study area is characterized by a continental arid desert climate, with low mean annual air temperature, little rainfall and high evaporation (Wu et al., 2015). The mean annual air temperature was approximately $-4{ }^{\circ} \mathrm{C}$, and the annual precipitation ranged from 200 to $400 \mathrm{~mm}$ (Chang et al., 2016). The permafrost type at our site is transition, and the active layer depth is $2.78 \pm 1.03 \mathrm{~m}$ (Chen et al., 2012). The dominant plant species in the study area were Kobresia capillifolia and Carex moorcroftii (Qin et al., 2014). Soils was classified as "felty", with a $\mathrm{pH}$ of 8.56 , and consisted of $30.96 \%$ silt and fine soils, $57.52 \%$ fine sand, and $10.68 \%$ coarse sand; soil bulk density is $1.41 \mathrm{~g} \mathrm{~cm}^{-3}$ within $0-40 \mathrm{~cm}$ depth of the soil layer (Qin et al., 2015b). The grassland in this area suffered from degradation due to permafrost degradation and external disturbance from grazing livestock and small mammals, i.e., plateau pikas (Yi et al., 2011; Qin et al., 2015a). As a result, a mosaic pattern of vegetation patches, bald patches with different sizes, and pika piles were common.

\subsection{Field observation}

In early June 2016 , three $100 \mathrm{~m} \times 100 \mathrm{~m}$ plots were established as replicates. Each $100 \times 100 \mathrm{~m}$ plot had a distance of less than $50 \mathrm{~m}$ which had similar plants and terrain. In each plot, six representative land surface types were selected: (1) large bald patch with a size larger than $9.0 \mathrm{~m}^{2}$ (LP), (2) medium bald patch with a size of $1.0-9.0 \mathrm{~m}^{2}$ (MP), (3) small bald patch with a size of less than $1.0 \mathrm{~m}^{2}(\mathrm{SP})$, (4) intact grassland patch (IG), (5) above pika tunnel (PT) and (6) old pika pile (PP; Fig. 1; Yi et al., 2016; Qin et al., 2018). There were no other mammals, e.g., marmot and zokor, in our study plots. All of the piles in each plot were created by plateau pikas. They were distinguished easily in aerial photographs. Large bald patches had less vegetation cover, and the smallest side was larger than $3 \mathrm{~m}$. Medium patches also covered less vegetation cover, and the largest side was in a range of 1 to $3 \mathrm{~m}$; small bald patches were 


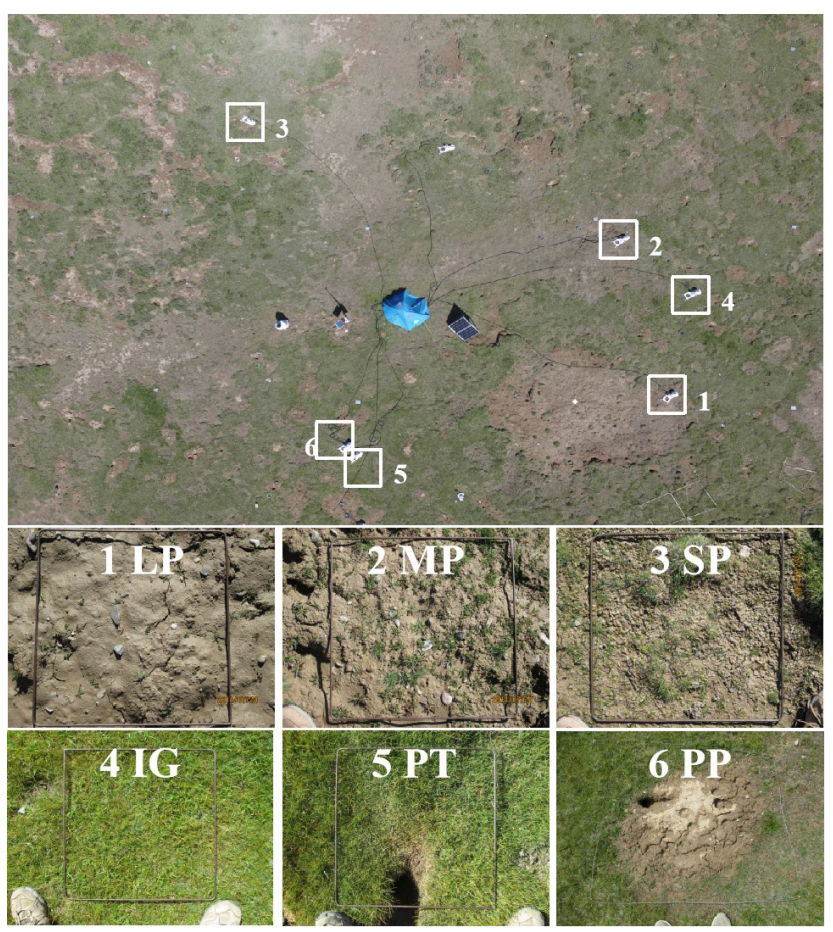

Figure 1. An aerial photo of field observation of ecosystem respiration at six surface types: (1) large bald patch (LP), (2) medium bald patch (MP), (3) small bald patch (SP), (4) intact grassland patch (IG), (5) above pika tunnel (PT) and (6) old Pika pile (PP).

characterized by less vegetation cover, and the largest side was less than $1 \mathrm{~m}$. Intact grassland was characterized by high vegetation cover, and no large and medium bare land was found. Pika tunnel and pika pile usually coexisted. Pika tunnel is approximately $6 \mathrm{~cm}$ in diameter, and pika pile is in the front of pika tunnel and is $60 \mathrm{~cm}$ in diameter or less in vegetation cover. We calculated the threshold area of large, medium and small patches by aerial photographs. Each aerial photograph has 12 million pixels. At a height of $20 \mathrm{~m}$, the resolution of each pixel is $\sim 1 \mathrm{~cm}$, and each photograph covers $\sim 26 \mathrm{~m} \times 35 \mathrm{~m}$ of ground. Pixels in each aerial image were first classified into two groups, i.e., vegetated or bare patches (Yi, 2017). Then patches with different sizes were created using the OpenCv Library. Finally, fractions of vegetation and bare patches (large, medium and small patches) were calculated. For each surface type in each plot, six $1 \mathrm{~m} \times 1 \mathrm{~m}$ quadrats were set up, of which three were used for soil-saturated hydraulic conductivity measurement and three were used for soil compactness measurement and soil and vegetation sampling. We also set up another three $1 \mathrm{~m} \times 1 \mathrm{~m}$ quadrats and three $2 \mathrm{~m} \times 2 \mathrm{~m}$ quadrats in each surface type in a $100 \mathrm{~m} \times 100 \mathrm{~m}$ plot for measuring soil temperature, soil moisture and ecosystem respiration.

A meteorological tower was established at our observation station in 2008 . Air temperature $\left({ }^{\circ} \mathrm{C}\right)$ at $2.0 \mathrm{~m}$ was measured by HMP45C (Vaisala; Helsinki, Finland), and precipi- tation was measured using an all-weather precipitation gauge (Geonor T-200B, Norway; Wu et al., 2015). Soil temperature and moisture at $10 \mathrm{~cm}$ were measured by using an automeasurement system (Decagon Inc., USA) from early June to late August. The system consisted of an EM50 logger and five 5TM sensors. The data were logged automatically every $30 \mathrm{~min}$. Soil-saturated hydraulic conductivity and compactness were measured once each month between June and August. Soil-saturated hydraulic conductivity was measured by a DualHead Infiltrometer (Decagon Inc., USA). The measurement process included a soak time of $15 \mathrm{~min}$ and a hold time of $20 \mathrm{~min}$ at the low pressure head $(5 \mathrm{~cm})$ and high pressure head $(15 \mathrm{~cm})$ with two cycles. Each measurement took $95 \mathrm{~min}$ altogether. Soil compactness was measured with the TJSD-750 (Hangzhou Top Instrument Co., LTD, Hangzhou, China) from the soil surface to $10 \mathrm{~cm}$ depth. Ecosystem respiration rates were measured using the LICOR-8150 Automated Soil $\mathrm{CO}_{2}$ Flux System, which was an accessory for the LI-8100A that could connect 16 individual chambers at one time and was sampled and controlled by the LI-8100A Analyzer Control Unit. The air temperature inside of the chamber was measured using the internal thermistor of the chamber. The ecosystem $\mathrm{CO}_{2}$ fluxes were calculated by the equation as follows:

$F_{\mathrm{c}}=\frac{10 V P_{0}\left(1-\frac{W_{0}}{1000}\right)}{R S\left(T_{0}+273.15\right)} \frac{\partial C^{\prime}}{\partial t}$,

where $F_{\mathrm{c}}$ is the soil $\mathrm{CO}_{2}$ efflux rate $\left.(\mu \mathrm{mol} \mathrm{m})^{-2} \mathrm{~s}^{-1}\right), V$ is volume $\left(\mathrm{cm}^{3}\right), P_{0}$ is the initial pressure $(\mathrm{kPa}), W_{0}$ is the initial water vapor mole fraction $\left(\mathrm{mmol} \mathrm{mol}^{-1}\right), R$ is the ideal gas constant $\left(\mathrm{J} \mathrm{K}^{-1} \mathrm{~mol}^{-1}\right), S$ is soil surface area $\left(\mathrm{cm}^{2}\right)$, $T_{0}$ is initial air temperature $\left({ }^{\circ} \mathrm{C}\right)$ and $\partial C^{\prime} / \partial t$ is the initial rate of change in the water-corrected $\mathrm{CO}_{2}$ mole fraction $\left(\mu \mathrm{mol}^{-1} \mathrm{~s}^{-1}\right)$.

Six LICOR-8100-104 long-term opaque chambers $(20 \mathrm{~cm}$ in diameter; LICOR, Inc., Lincoln, NE, USA) were used to measure alternately between three replicates for six land surface types. Therefore, at least 3 days were required to complete one rotation of measurements of ecosystem respiration. To measure ecosystem respiration, 18 polyvinyl chloride collars with a $20 \mathrm{~cm}$ inner diameter and $12 \mathrm{~cm}$ height were inserted into the soil, with 3-4cm exposed to the air (Qin and $\mathrm{Yi}, 2013)$. All of the collars were installed at least $24 \mathrm{~h}$ before the first measurement to reduce disturbance-induced ecosystem $\mathrm{CO}_{2}$ effluxes. Ecosystem respiration rates were measured every 7-10 days from 16 June to 20 August 2016, depending on weather conditions. A round-the-clock measurement protocol was carried out, and ecosystem respiration rates were measured every $30 \mathrm{~min}$. Each measurement took $1 \mathrm{~min}$ and $45 \mathrm{~s}$, including the pre-purge ( $10 \mathrm{~s})$, dead band (15 s), observation length (1 min) and post-purge $20 \mathrm{~s}$. 


\subsection{Soil and vegetation sampling}

Soil samples were collected during the period of late July to early August 2016. In each surface type of each plot, five soil cores were collected using a stainless-steel auger $(5 \mathrm{~cm}$ in diameter) at depths of $0-10,10-20,20-30$ and $30-40 \mathrm{~cm}$ and were combined into one composite sample for each depth in each quadrat. Another five soil cores were sampled by a cylindrical cutting ring $(7 \mathrm{~cm}$ in diameter and $5.2 \mathrm{~cm}$ in depth) to determine soil bulk density from each land surface type. Pika tunnels were approximately $6 \mathrm{~cm}$ in diameter and $40 \mathrm{~cm}$ in depth. Therefore, soil samples were available to collect at the depth of $40 \mathrm{~cm}$. In total, 512 soil samples were collected. Soil samples were firstly air dried; then gravel and stone were removed from the samples with manual sieving, and they were finally weighed. The remaining soil samples with a diameter of less than $2 \mathrm{~mm}$ were ground to pass through a $0.25 \mathrm{~mm}$ sieve for analysis of soil organic carbon (SOC) and soil total nitrogen (TN) concentration. SOC was measured by dichromate oxidation using the WalkleyBlack acid digestion method (Nelson and Sommers, 1982). TN was determined by digestion and then tested using a flow injection analysis system (FIAstar 5000, Foss Inc., Sweden). Aboveground and belowground biomasses were determined within a $1 \mathrm{~m} \times 1 \mathrm{~m}$ quadrat on 4 August 2016 during peak biomass and species diversity. There were a total of 108 aboveground and belowground vegetation samples ( 3 plots $\times 6$ land surface types $\times 3$ replicates) from the study area. Aboveground biomass was determined by clipping all aboveground living plants at the ground level, drying them (oven-dried at $65^{\circ} \mathrm{C}$ for $48 \mathrm{~h}$ ) and weighing them. Belowground biomass was sampled by collecting five soil columns, and each soil column was $5 \mathrm{~cm}$ in diameter and $40 \mathrm{~cm}$ in depth. Soil cores were washed with a gentle spray of water over a fine mesh screen until soil separated from the roots, and then they were dried (oven-dried at $65^{\circ} \mathrm{C}$ for $48 \mathrm{~h}$ ) and weighed.

\subsection{Statistical analysis}

The soil organic $\mathrm{C}$ and total $\mathrm{N}$ densities in different land surface were calculated using Eqs. (2) and (3):

$\mathrm{SOC}=\sum_{i=1}^{n} \rho \cdot\left(1-\sigma_{\text {gravel }}\right) \cdot C_{\mathrm{SOC}} \cdot D_{i}$,
$\mathrm{TN}=\sum_{i=1}^{n} \rho \cdot\left(1-\sigma_{\text {gravel }}\right) \cdot C_{\mathrm{TN}} \cdot D_{i}$,

where SOC is soil organic $\mathrm{C}$ density $\left(\mathrm{kg} \mathrm{m}^{-2}\right)$, $\mathrm{TN}$ is soil total $\mathrm{N}$ density $\left(\mathrm{kg} \mathrm{m}^{-2}\right), \rho$ is the soil bulk density $\left(\mathrm{g} \mathrm{cm}^{-3}\right)$, $\sigma_{\text {garvel }}$ is the relative volume of gravel $(\% w / w), C_{\mathrm{SOC}}$ is soil organic $\mathrm{C}$ content $\left(\mathrm{g} \mathrm{kg}^{-1}\right), C_{\mathrm{TN}}$ is soil total $\mathrm{N}$ content $\left(\mathrm{g} \mathrm{kg}^{-1}\right)$ and $D_{i}$ is soil thickness $(\mathrm{cm})$ at layer $i(i=1,2,3$ and 4).
The data were presented as mean \pm standard deviation. Statistical analyses were performed using the SPSS 17.0 statistical software package (SPSS Inc., Chicago, IL, USA). One-way analysis of variance (ANOVA) and a multicomparison of the least significant difference (LSD) test were used to determine differences at the $p=0.05$ level. The relationships of ecosystem respiration with biotic and abiotic factors were analyzed by Pearson correlation analysis using R.

\section{Results}

\subsection{Ecosystem respiration}

Ecosystem respiration showed significant difference among varied land surface types during the growing season (Table $1 ; P<0.001)$. Except for pika pile, ecosystem respiration was at a maximum in August and at a minimum in June (Fig. 2). In June, ecosystem respiration in intact grassland, above pika tunnel, small patch and pika pile had no significant difference, and the lowest ecosystem respiration was found in large and medium patches (Fig. 2). Average ecosystem respiration in intact grassland was $4.01 \mu \mathrm{mol} \mathrm{m}^{-2} \mathrm{~s}^{-1}$ in July, which was $24.35 \%$ to $137.39 \%$ higher than other surface types (Fig. 2). In August, average ecosystem respiration was 4.07 and $4.85 \mu \mathrm{mol} \mathrm{m} \mathrm{m}^{-2} \mathrm{~s}^{-1}$ for intact grassland and above pika tunnel, respectively, $2.59-3.81 \mu \mathrm{mol} \mathrm{m}^{-2} \mathrm{~s}^{-1}$ for bald patches, and $1.18 \mu \mathrm{mol} \mathrm{m}^{-2} \mathrm{~s}^{-1}$ for pika pile (Fig. 2).

\subsection{Microclimate and soil hydrothermal characteristics}

Mean temperature and total rainfall during the growing season from 1 May to 30 September 2016 were $6.18^{\circ} \mathrm{C}$ and $343.4 \mathrm{~mm}$, respectively (Fig. 3). Soil temperature and moisture were significantly different among various land surface types (Table $1, P<0.05$ ). The monthly average soil temperature was in a range of $8.20-13.72{ }^{\circ} \mathrm{C}$ from June to August, which was approximately $1-3^{\circ}$ higher in pika pile and bald patches than the intact grassland (Fig. $4 \mathrm{a} ; P<0.05$ ). The monthly mean soil moisture from June to August was approximately $30 \%$ for intact grassland and above pika tunnel, $25 \%$ for small patch and pika pile, and $20 \%$ for larger and medium patch (Fig. 4b). Soil-saturated hydraulic conductivity also showed significant variation in different land surface types ( $P=0.027$, Table 2$)$. For example, soil-saturated hydraulic conductivity in large bald patch, medium bald patch, small bald patch, intact grassland patch, above pika tunnel and old pika pile was $1.54,1.53,2.14,2.13,2.12$ and $2.58 \mathrm{~cm} \mathrm{~h}^{-1}$, respectively (Fig. 5). Soil-saturated hydraulic conductivity in intact grassland patch was approximately $40 \%$ higher than medium and large patches and $17 \%$ lower than pika pile, while there was no significant difference between intact grassland patch, small patch and above pika tunnel $(P>0.05)$. 
Table 1. ANOVA results of soil temperature, soil moisture and ecosystem respiration in different land surface types.

\begin{tabular}{rrrr|rrr|rrr}
\hline & \multicolumn{3}{c}{ Soil temperature } & \multicolumn{3}{c|}{ Soil moisture } & \multicolumn{3}{c}{ Ecosystem respiration } \\
\cline { 2 - 10 } & June & July & August & June & July & August & June & July & August \\
\hline$F$ & 8.614 & 10.955 & 1.806 & 387.472 & 210.878 & 97.060 & 5.270 & 10.447 & 8.855 \\
$P$ & $<0.001$ & $<0.001$ & 0.106 & $<0.001$ & $<0.001$ & $<0.001$ & 0.001 & $<0.001$ & $<0.001$ \\
\hline
\end{tabular}
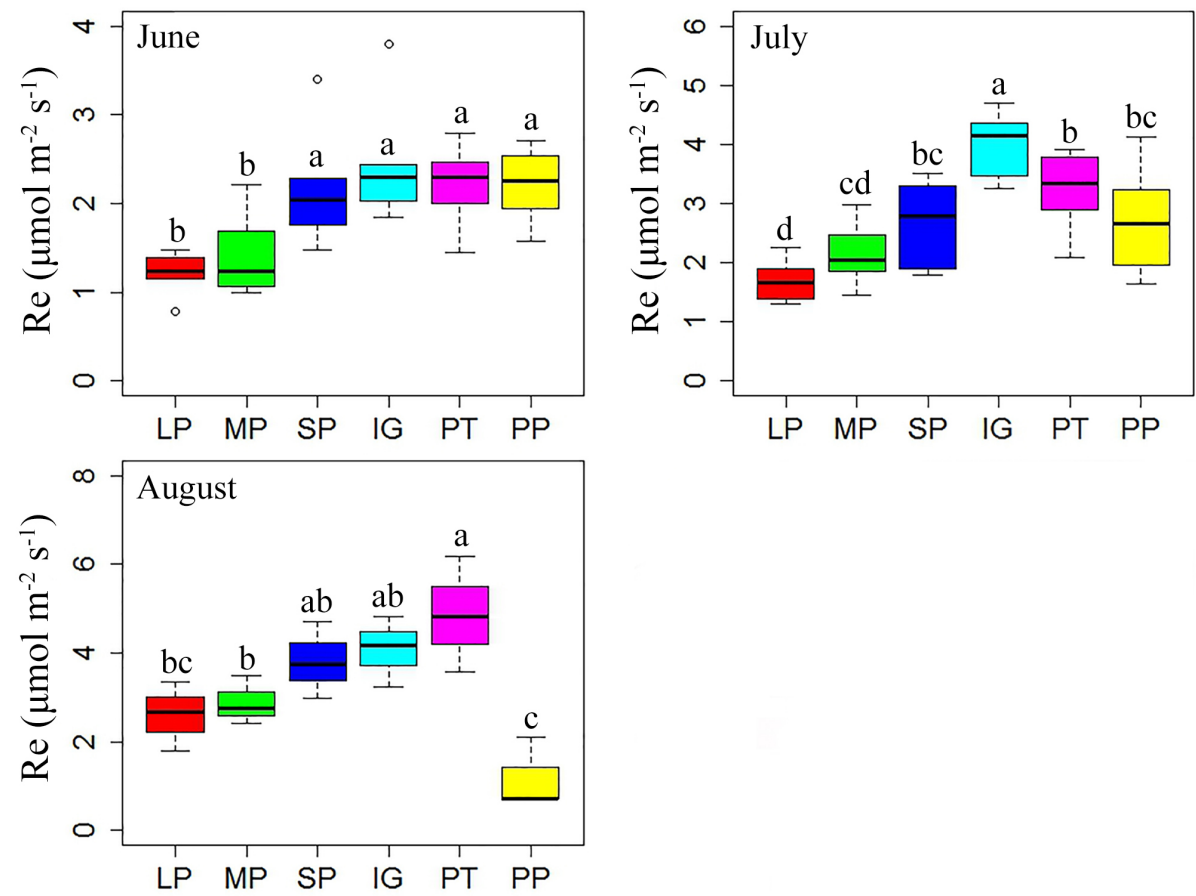

Figure 2. Ecosystem respiration of different surface types: (1) large bald patch (LP), (2) medium bald patch (MP), (3) small bald patch (SP), (4) intact grassland patch (IG), (5) above pika tunnel (PT) and (6) old pika pile (PP). The upper solid lines, the bottom solid lines, the bold solid horizontal line and the empty dot are the maximum value, minimum value, median and abnormal value, respectively. Letters on the error bars indicate significant differences among different surface types at $P<0.05$.

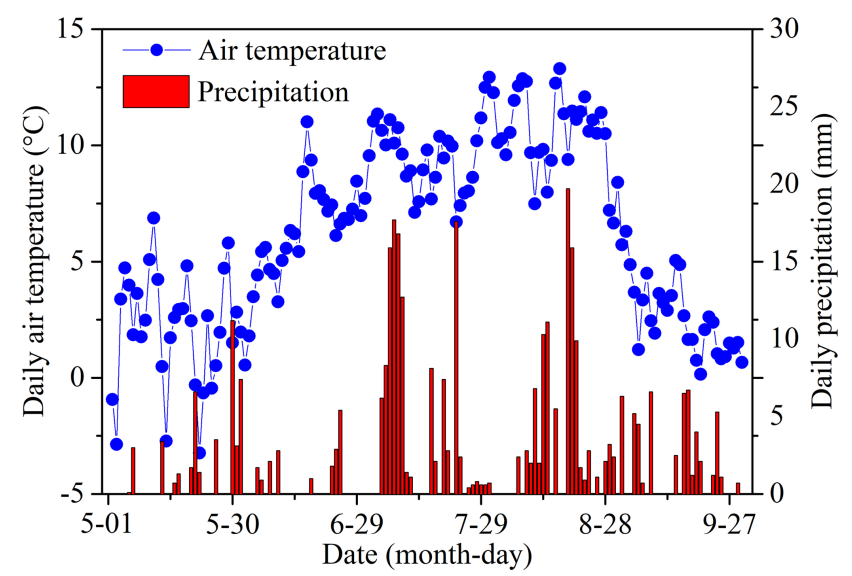

Figure 3. Daily average air temperature and precipitation of the study site in 2016 .

\subsection{Soil and vegetation properties}

Soil and vegetation properties showed significant variation in different land surface types (Table $2 ; P<0.001$ ). Soil compactness was over $0.30 \mathrm{~Pa}$ in intact grassland and above pika tunnel, approximately $0.20 \mathrm{~Pa}$ for bald patches, and less than $0.10 \mathrm{~Pa}$ for pika pile (Fig. 6). Mean SOC and TN density in intact grassland were $52.45 \%$ and $59.14 \%$ less than above pika tunnel, whereas they were $9.69 \%-30.12 \%$ and $22.47 \%-109.62 \%$ higher than pika pile and bald patches (Fig. 7). Aboveground and belowground biomasses in intact grassland were approximately $30 \%$ higher than above pika tunnel, $90 \%$ higher than pika pile, and $123 \%-252 \%$ and $134 \%-289 \%$ higher than bald patches (Fig. 8a, b).

\subsection{Factors regulating ecosystem respiration}

We analyzed the relationships of ecosystem respiration with biotic and abiotic factors for six land surface types (Fig. 9). 
Table 2. ANOVA results of soil compactness, aboveground biomass, belowground biomass, soil hydraulic conductivity, and SOC and TN density in different land surface types.

\begin{tabular}{rrrrrrr}
\hline & $\begin{array}{r}\text { Soil } \\
\text { compactness }\end{array}$ & $\begin{array}{r}\text { Aboveground } \\
\text { biomass }\end{array}$ & $\begin{array}{r}\text { Belowground } \\
\text { biomass }\end{array}$ & $\begin{array}{r}\text { Saturated hydraulic } \\
\text { conductivity }\end{array}$ & $\begin{array}{r}\text { SOC } \\
\text { density }\end{array}$ & $\begin{array}{r}\text { TN } \\
\text { density }\end{array}$ \\
\hline$F$ & 81.506 & 6.193 & 12.925 & 2.752 & 145.942 & 50.567 \\
$P$ & $<0.001$ & 0.002 & $<0.001$ & 0.027 & $<0.001$ & $<0.001$ \\
\hline
\end{tabular}
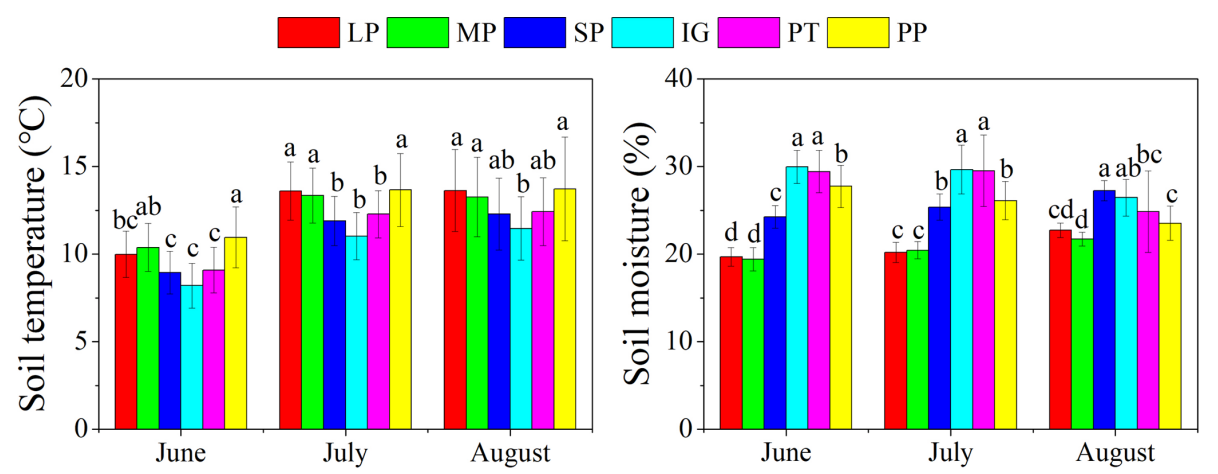

Figure 4. Monthly average soil temperature and soil moisture at $10 \mathrm{~cm}$ depth in different surface types: (1) large bald patch (LP), (2) medium bald patch (MP), (3) small bald patch (SP), (4) intact grassland patch (IG), (5) above pika tunnel (PT) and (6) old pika pile (PP).

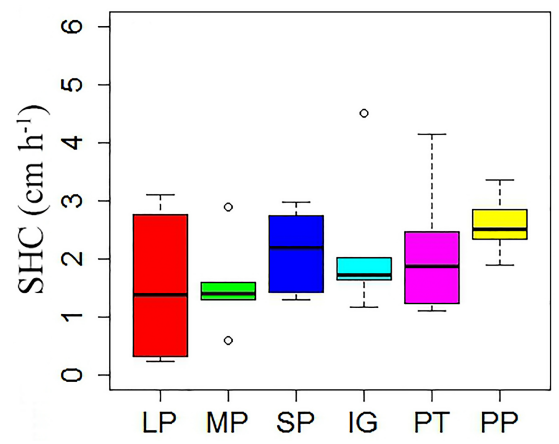

Figure 5. Soil-saturated hydraulic conductivity (SHC) in different surface types: (1) large bald patch (LP), (2) medium bald patch (MP), (3) small bald patch (SP), (4) intact grassland patch (IG), (5) above pika tunnel (PT) and (6) old pika pile (PP).

Correlation analysis showed that ecosystem respiration had no significant correlation with soil temperature $(P>0.05$; Fig. 9). However, ecosystem respiration was significantly and positively related to soil moisture $(P<0.01)$, soil total nitrogen $(P<0.05)$, and aboveground $(P<0.05)$ and belowground biomasses $(P<0.05$; Fig. 9$)$.

\section{Discussion}

\subsection{Effect of pika disturbance on ecosystem respiration}

Pika burrowing activities increased oxygen content in deep soil, which contributed to the decomposition of soil organic

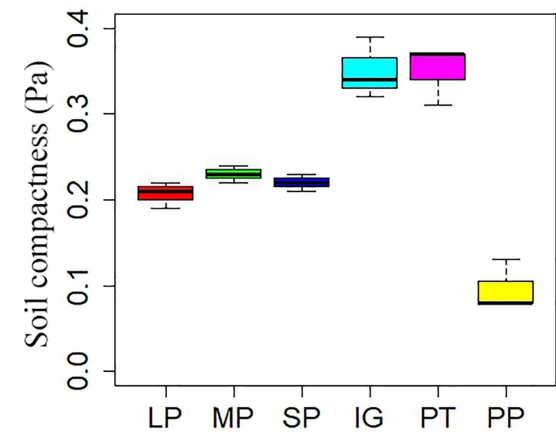

Figure 6. Soil compactness in different surface types: (1) large bald patch (LP), (2) medium bald patch (MP), (3) small bald patch (SP), (4) intact grassland patch (IG), (5) above pika tunnel (PT) and (6) old pika pile (PP).

matter (Martin, 2003). The deposition of urine and feces by small herbivorous mammals could also promote ecosystem nutrition circulation (Clark et al., 2005). It was suggested that excreta deposited by pikas and frequently found in or near their burrows supplied organic $\mathrm{C}$ available to microbial decomposition with an increase in ecosystem $\mathrm{CO}_{2}$ emission (Cao et al., 2004). Indeed, SOC and TN densities reached up to 14.54 and $0.98 \mathrm{~kg} \mathrm{~m}^{-2}$ in above pika tunnel, which was 2.45 and 2.10 times higher, respectively, than that in intact grassland (Fig. 7). The consistent results reported that the contents of available soil nutrients around the pika burrow were higher than those in control sites on an alpine meadow (Zhang et al., 2016). We also found that 

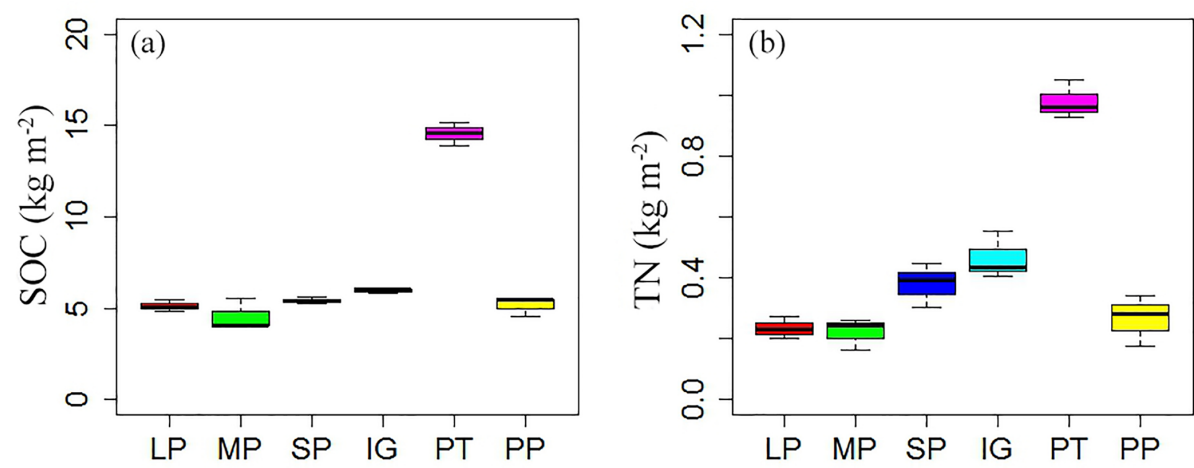

Figure 7. Soil organic carbon (SOC; a) and total nitrogen (TN; b) density of different surface types: (1) large bald patch (LP), (2) medium bald patch (MP), (3) small bald patch (SP), (4) intact grassland patch (IG), (5) above pika tunnel (PT) and (6) old pika pile (PP).
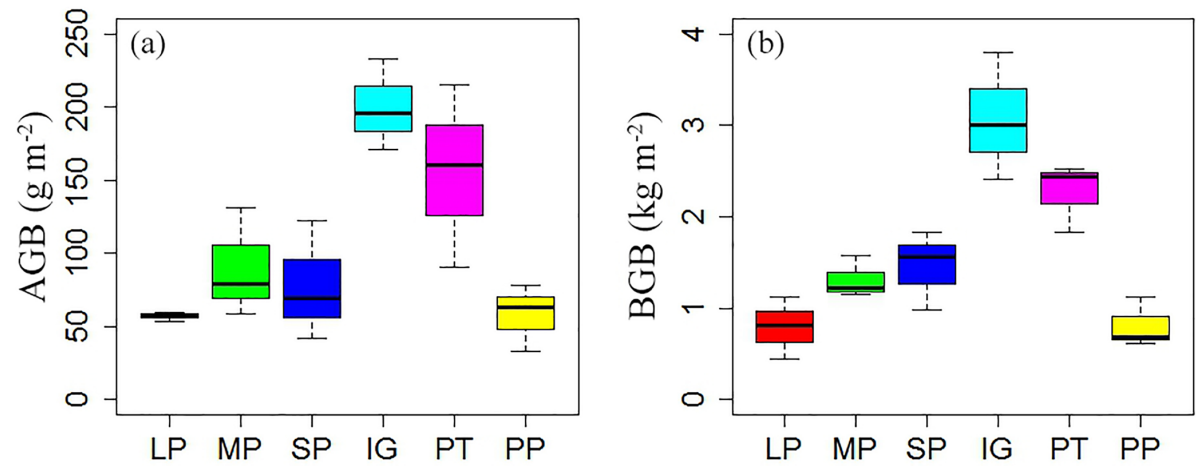

Figure 8. Aboveground biomass (AGB) (a) and belowground biomass (BGB) (b) in different surface types: (1) large bald patch (LP), (2) medium bald patch (MP), (3) small bald patch (SP), (4) intact grassland patch (IG), (5) above pika tunnel (PT) and (6) old pika pile (PP).

SOC and TN densities in pika pile decreased $13.35 \%$ and $42.93 \%$ when compared to intact grassland. This was because pika burrowing activity transferred deeper, nutrientpoor soil to the soil surface, improved soil aeration, increased the rate of organic carbon mineralization and soil erosion, and took away soil nutrition (Wei et al., 2006; Qin et al., 2015a; Chen et al., 2017). However, except in July, no significant difference in Re was found between intact grassland and above pika tunnel, while Re in pika pile was $42.08 \%$ less than intact grassland (Fig. 2). A similar result was also found in an alpine meadow on the QTP (Peng et al., 2015), which indicated that ecosystem respiration decreased with increasing of pika holes because of grassland biomass regulating soil $\mathrm{C}$ and $\mathrm{N}$, with an increasing number of pika holes. These results confirmed that pika disturbance did not increase ecosystem carbon emission directly but facilitated $\mathrm{CO}_{2}$ emission into the atmosphere through pika holes (Qin et al., 2015a). The difference in ecosystem respiration between intact grassland and pika piles was mainly related to changes in vegetation biomass and soil moisture. For example, both aboveground and belowground biomasses decreased $244.62 \%$ and $279.89 \%$ in pika piles compared with intact grassland (Fig. 8). The reduction in vegetation biomass production decreased aboveground plant respiration and root respiration by decreasing carbon allocation (e.g., root exudates, litter and available SOC; Raich and Potter, 1995; Högberg et al., 2002; Yang et al., 2018). Consistent with previous studies which demonstrated that pika burrowing activity increased the water infiltration rate (Hogan, 2010; Wilson and Smith, 2015), our results also showed that soil-saturated hydraulic conductivity in pika pile was significantly higher than bald and vegetation patches (Fig. 5). Nevertheless, the increased water infiltration was unable to increase soil moisture in pika piles. For example, soil moisture in pika piles was approximately $5 \%$ lower than intact grassland (Fig. 4). Our result was inconsistent with previous studies, which reported that old pika mound had the highest soil moisture during the summer (Ma et al., 2018) and that moderate pika burrowing activities increased surface soil moisture ( $\mathrm{Li}$ and Zhang, 2006). This difference may have contributed to the high pika density in alpine meadow (Guo et al., 2017). Moreover, pika piles were loose (Fig. 6) with less vegetation cover (Fig. 8), which was not beneficial for soil moisture storage. 


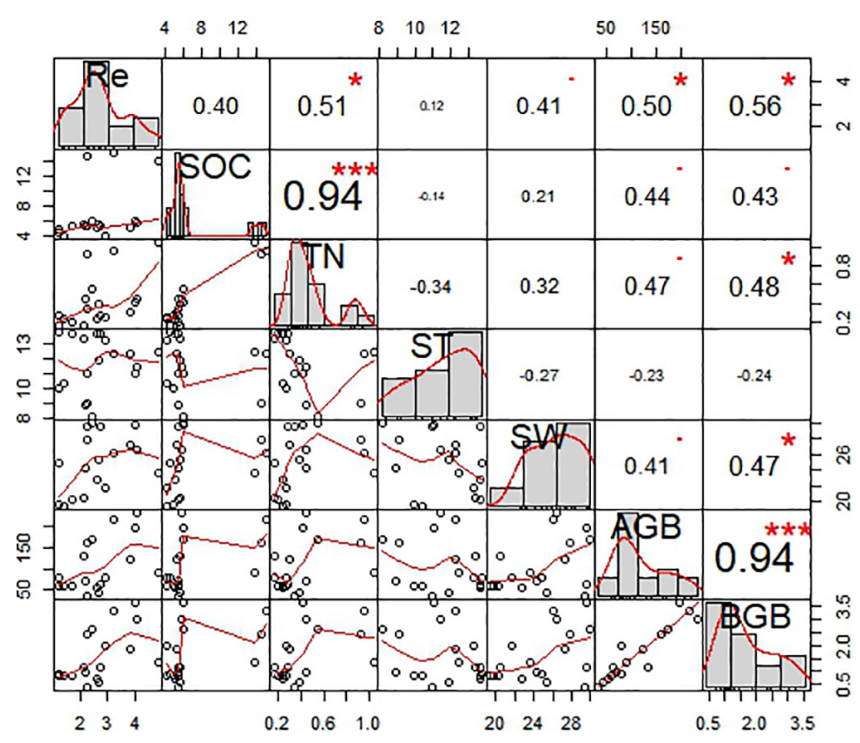

Figure 9. The correlation coefficient charts between ecosystem respiration (Re) and biotic and abiotic factors for all six land surface types. The diagonal line in the figure shows the distributions of the variables themselves. The red line means the frequency distribution of variables. The lower triangle (left bottom) in the figure shows scatter plots of the two properties. The upper triangle (upper right) in the figure indicates the correlation values of the two parameters; the asterisk indicates the degree of significance ${ }^{* * *}$ indicates significant differences at $P<0.001,{ }^{* *}$ indicates significant differences at $P<0.01$ and ${ }^{*}$ indicates significant differences at $P<0.05)$. The bold bigger numbers mean the higher correlation.

\subsection{Effect of patchiness on ecosystem respiration}

Our results clearly showed that patchiness resulted in significant reduction in ecosystem carbon emissions. Compared with intact grassland, ecosystem respiration decreased approximately $17 \%-48 \%$ for bald patches (Fig. 2). Two possible mechanisms could account for the effects of patchiness on ecosystem respiration. On the one hand, the reduction in SOC and TN decreased microbial respiration by decreasing substrate supply to microbes in the rhizosphere (Nobili et al., 2001; Scott-Denton et al., 2010). Our results indicated that patchiness caused evident loss of SOC and TN (Fig. 7) due to reduction in $\mathrm{C}$ input from vegetation and increased C output from soil erosion (Qin et al., 2018). Previous studies have shown that the spatial heterogeneity of soil respiration was attributed to uneven soil organic carbon and total nitrogen content (Xu and Qi, 2010). Soil organic carbon was considered to be the basic substrate of $\mathrm{CO}_{2}$ emission by microbial decomposition (Sikora and Mccoy, 1990), and soil total $\mathrm{N}$ enhanced ecosystem $\mathrm{CO}_{2}$ emissions by providing a source of protein for microbial growth (Tewary et al., 1982). On the other hand, low moisture availability limits microbial respiration by restricting access to $\mathrm{C}$ substrates, reducing the diffusion of $\mathrm{C}$ substrates and extracellular enzymes, and limiting microbial mobility (Yuste et al., 2003; Wang et al., 2014). Our results showed that soil moisture in large and medium patches decreased by $10 \%$ compared to intact grassland (Fig. 4). Previous studies reported that the soil compaction of bald patches decreased the rate of water infiltration (Wuest et al., 2006; Wilson and Smith, 2015); this was similar to our results, which showed that bald patches had less saturated soil hydraulic conductivity (Fig. 5). Low vegetation cover in bald patches was not beneficial for water retention and utilization, where most of soil water was mainly lost by means of evaporation (Yi et al., 2014). We measured evaporation of the intact grassland, isolated grassland, large patches, medium patches and small patches, starting in early June 2016. Results after 3 years indicated that evaporation in bald patches was higher than intact grassland (data were not shown here).

\subsection{Factors that affected ecosystem respiration}

Most previous studies showed that soil temperature explained most of the temporal variation in ecosystem respiration in the alpine grassland on the QTP (Lin et al., 2011; Qin et al., 2015c; Zhang et al., 2017). Our results indicated that soil temperature in pika piles and bald patches was approximately 1 to $3{ }^{\circ} \mathrm{C}$ higher than intact grassland (Fig. 4), which mainly resulted from the heterogeneity of the surface albedo, surface soil water retention, heat conduction properties and radiation (Beringer et al., 2005; Pielke, 2005; Yi et al., 2013; You et al., 2017). It was suggested that pika disturbance creates a better soil temperature buffer for them to avoid the extreme cold in winter (Ma et al., 2018), whereas the high soil temperature in bald patch was a disadvantage for the recovery of vegetation because the patch surface had the smallest soil moisture content (Fig. 4) and the largest daily range of soil temperatures (Ma et al., 2018). It was well known that the rising soil temperature under natural conditions enhanced ecosystem respiration by stimulating decomposition of soil organic matter (Conant et al., 2008), increasing plant biomass (Yi et al., 2014) and activity of microbial enzymes (Bond-Lamberty and Thomson, 2010). However, an obvious relationship between Re and soil temperature was not found in the present study (Fig. 9), which suggested that other factors involved in controlling Re were induced by pika disturbance and patchiness. Our results showed that Re was positively correlated with soil moisture, soil total nitrogen, and aboveground and belowground biomasses (Fig. 9). Pika disturbance and patchiness led to the drying and loosening of soil (Figs. 4 and 6). It was considered that loose, dry surface sediments and strong winds were the primary factors responsible for soil erosion (Dong et al., 2010), and wind erosion was especially common in arid and semi-arid regions (Zhang and Dong, 2014). This resulted in the reduction in soil organic carbon, total nitrogen and vegetation biomass (Figs. 7 and 8). The alteration of these biotic and abiotic factors induced by pika disturbance and patchiness led to the decline 
in ecosystem respiration. Nevertheless, the decline in ecosystem respiration did not completely offset the sequestration of $\mathrm{C}$ fixed by photosynthesis because of the lower vegetation cover in bald patches and pika piles. Given the large area covered by bald patches in alpine grasslands, patchiness was more susceptible to erosion and exerted greater influence on ecosystem respiration than pika disturbance. A recent study also reported that bald patches of various sizes in the grasslands played a much more important role than pika direct disturbance in reducing vegetation cover, aboveground biomass, soil carbon and nitrogen (Yi et al., 2016).

\subsection{Effect of pika disturbance on patchiness}

Natural vegetation patches, bald patches with different sizes and pika piles coexisted on the alpine meadow (Fig. 1), which supported the fact that alpine grassland also experienced fragmentation (Qin et al., 2018). Several proposed mechanisms may be accounted for in the formation and development of patchiness in alpine grassland. As one of the dominant forms of land utilization, alpine grasslands are widely used for grazing. Previous studies suggested that overgrazing destroyed the original vegetation and led to a decrease in the coverage and looseness of soil (Dong et al., 2014), which was prone to forming bald patch due to soil erosion (Fécan et al., 1999; Zhang and Dong, 2014). Other than livestock, alpine grassland is also a habitat for many small mammals, such as the plateau pika, zokor (Eospalax fontanierii), marmot (Marmota himalayana) and fox (Vulpes ferrilata). Pikas were considered to be creating a patchy matrix by changing soil properties (Chen et al., 2017), by digging tunnels and through burying activities (Dong et al., 2013). On the one hand, pikas bury vegetation in freshly excavated soil; then small bare soil patches and further large soil patches are formed by linking small bare soil patches by wind and/or water (Wei et al., 2006; Ma et al., 2018). On the other hand, pikas dig tunnels underground. Although pika-made burrows are the primary homes for a wide variety of small birds and lizards (Smith and Foggin, 1999), the collapse of pika tunnels results in the emergence of bald soil patches (Zhou et al., 2003; Cao et al., 2010). Moreover, alpine grassland is underlain by extensive permafrost (Cheng and $\mathrm{Wu}, 2007)$. The repeated freeze-thaw causes the cracking of the sod around the barren area (Yang et al., 2003) and creates preconditions for the forming bald patch. However, to date, there is no direct evidence to demonstrate the potential mechanism for forming and developing patchiness for alpine grassland on the QTP. It is, therefore, critical to perform long-term repeated monitoring studies to determine whether bald patches are developed from pika piles or burrow tunnels and to determine the major factors affecting bald patch expansion (Yi et al., 2016).

\section{Conclusions}

In this study, we investigated soil physicochemical properties, vegetation biomass and ecosystem respiration (Re) in six land surface types originating from pika disturbance and patchiness. We also analyzed the dominant factors regulating the Re. Our results showed that pika disturbance and patchiness decreased soil moisture but increased soil temperature, which may be conducive to pikas surviving in cold season but disadvantageous for vegetation growth. Patchiness caused an evident decrease in SOC and TN density, while both SOC and TN density showed a different response in pika piles and burrows. Both pika disturbance and patchiness decreased ecosystem carbon emission, and ecosystem respiration strongly correlated with soil moisture, TN and vegetation biomass. Our results indicated that pika disturbance and patchiness led to the changing of ecosystem respiration process, owing to the drying of soil and the reduction in substrate supply. However, the decline in ecosystem respiration may not be able to offset the sequestration of $\mathrm{C}$ fixed by photosynthesis.

Data availability. Data used in this study are archived by the authors and are available on request.

Author contributions. SY and YD designed the study. YQ, WZ, YQ, JC and ZW performed field observation and sampling. All authors contributed to the discussion of the results. YQ led the writing of the paper, and all co-authors contributed to it.

Competing interests. The authors declare that they have no conflict of interest.

Acknowledgements. The authors would like to thank Jun Zhang and Bingbing Bai for their help in field sampling. This study was jointly supported by grants from the National Natural Science Foundation (41601064), the National Key Research and Development Program of China (2018YFC0406601), the National Natural Science Foundation of China (41690142), the independent grants from the State Key Laboratory of Cryosphere Sciences (SKLCS-ZZ-2018), and the science and technology support program of the Guizhou Science and Technology Agency, "The Key technology and engineering demonstration of farmland system control and restoration in Tongren mercury polluted area” (Qiankehezhicheng[2017]2967).

Review statement. This paper was edited by Michael Weintraub and reviewed by three anonymous referees. 


\section{References}

Ahlström, A., Xia, J., Arneth, A., Luo, Y., and Smith, B.: Importance of vegetation dynamics for future terrestrial carbon cycling, Environ. Res. Lett., 10, 1-11, 2015.

Baldi, G., Guerschman, J. P., and Paruelo, J. M.: Characterizing fragmentation in temperate South America grasslands, Agr. Ecosyst. Environ., 116, 197-208, 2006.

Beringer, J., Chapin, F. S., Thompson, C. C., and McGuire, A. D.: Surface energyexchanges along a tundra-forest transition and feedbacks to climate, Agr. Forest Meteorol., 131, 143-161, 2005.

Bestelmeyer, B. T., Ward, J. P., Herrick, J. E., and Tugel, A. J.: Fragmentation effects on soil aggregate stability in a patchy arid grassland, Rangeland Ecol. Manag., 59, 406-415, 2006.

Bond-Lamberty, B. and Thomson, A.: Temperature-associated increases in the global soil respiration record, Nature, 464, 579$582,2010$.

Canadell, J. G., Kirschbaum, M. U. F., Kurz, W. A., Sanz, M. J., Schlamadinger, B., and Yamagata, Y.: Factoring out natural and indirect human effects on terrestrial carbon sources and sinks, Environ. Sci. Policy, 10, 370-384, 2007.

Cao, G., Long, R., Zhang, F., Lin, L., Li, Y., and Liang, D.: Mechanism of denuded pits developing in degraded alpine Kobresia humilis meadow in the Three Rivers Source Region, Grassland Turf, 30, 16-21, 2010 (in Chinese with English abstract).

Cao, G. M., Tang, Y. H., Mo, W. H., Wang, Y. S., Li, Y. N., and Zhao, X. Q.: Grazing intensity alters soil respiration in an alpine meadow on the Tibetan plateau, Soil Biol. Biochem., 36, 237243, 2004

Chang, Y., Ding, Y., Zhao, Q., and Zhang, S.: Remote estimation of terrestrial evapotranspiration by Landsat $5 \mathrm{TM}$ and the SEBAL model in cold and high-altitude regions: A case study of the upper reach of the Shule River Basin, China, Hydrol. Process., 31, 514-524, 2016.

Chen, J., Yi, S., and Qin, Y.: The contribution of plateau pika disturbance and erosion on patchy alpine grassland soil on the Qinghai-Tibetan Plateau: Implications for grassland restoration, Geoderma, 297, 1-9, 2017.

Chen, S., Liu, W., Qin, X., Liu, Y., Zhang, T., Chen, K., Hu, F., Ren, J., and Qin, D.: Response characteristics of vegetation and soil environment to permafrost degradation in the upstream regions of the Shule River Basin, Environ. Res. Lett., 7, 045406, https://doi.org/10.1088/1748-9326/7/4/045406, 2012.

Cheng, G. and Wu, T.: Responses of permafrost to climate change and their environmental significance, Qinghai-tibet plateau, J. Geophys. Res., 112, 1-10, 2007.

Chimner, R. A. and Welker, J. M.: Ecosystem Respiration Responses to Experimental Manipulations of Winter and Summer Precipitation in a Mixedgrass Prairie, WY, USA, Biogeochemistry, 73, 257-270, 2005.

Clark, J. E., Hellgren, E. C., Parsons, J. L., Jorgensen, E. E., Engle, D. M., and Leslie, D. M.: Nitrogen outputs from fecal and urine deposition of small mammals: implications for nitrogen cycling, Oecologia, 144, 447-455, 2005.

Conant, R. T., Steinweg, J. M., Haddix, M. L., Paul, E. A., Plante, A. F., and Six, J.: Experimental warming shows that decomposition temperature sensitivity increases with soil organic matter recalcitrance, Ecology, 89, 2384-2391, 2008.
Cox, P. M., Betts, R. A., Jones, C. D., Spall, S. A., and Totterdell, I. J.: Acceleration of global warming due to carbon-cycle feedbacks in a coupled climate model, Nature, 408, 184-187, 2000.

Davidson, A. D. and Lightfoot, D. C.: Burrowing rodents increase landscape heterogeneity in a desert grassland, J. Arid. Environ., 72, 1133-1145, 2008.

Defries, R. S., Field, C. B., Fung, I., Collatz, G. J., and Bounoua, L.: Combining satellite data and biogeochemical models to estimate global effects of human-induced land cover change on carbon emissions and primary productivity, Global. Biogeochem. Cy., 13, 803-815, 1999.

Dong, Q. M., Zhao, X. Q., Wu, G. L., Shi, J. J., and Ren, G. H.: A review of formation mechanism and restoration measures of "black-soil-type" degraded grassland in the qinghai-tibetan plateau, Environ. Earth. Sci., 70, 2359-2370, 2013.

Dong, S. K., Wang, X. X., Liu, S. L., Li, Y. Y., Su, X. K., Wen, L., and Zhu, L.: Reproductive responses of alpine plants to grassland degradation and artificial restoration in the Qinghai-Tibetan Plateau, Grass. Forage Sci., 70, 229-238, 2014.

Dong, Z. B., Hu, G. Y., Yan, C. Z., Wang, W. L., and Lu, J. F.: Aeolian desertification and its causes in the Zoige Plateau of China's Qinghai-Tibetan Plateau, Environ. Earth Sci., 59, 17311740, 2010.

Dregne, H. E.: Land degradation in the drylands, Arid Soil Res. Rehab., 16, 99-132, 2002.

Fécan, F., Marticorena, B., and Bergametti, G.: Parametrization of the increase of the aeolian erosion threshold wind friction velocity due to soil moisture for arid and semi-arid areas, Ann. Geophys., 17, 149-157, https://doi.org/10.1007/s00585-999-0149-7, 1999.

Flanagan, L. B. and Johnson, B. G.: Interacting effects of temperature, soil moisture and plant biomass production on ecosystem respiration in a northern temperate grassland, Agr. Forest Meteorol., 130, 237-253, 2005.

Grogan, P. and Jonasson, S.: Temperature and substrate controls on intra-annual variation in ecosystem respiration in two subarctic vegetation types, Glob. Change Biol., 11, 465-475, 2005.

Guo, X. L., Yi, S. H., Qin, Y., and Chen, J. J.: Habitat environment affects the distribution of plateau pikas: a study based on an unmanned aerial vehicle, Pratacul. Sci., 34, 1306-1313, 2017 (in Chinese with English abstract).

Herkert, J. R., Reinking, D. L., Wiedenfeld, D. A., Winter, M., Zimmerman, J. L., Jensen, W. E., Finck, E. J., Koford, R. R., Wolfe, D. H., Sherrod, S. K., Jenkins, M. A., Faaborg, J., and Robinson, S. K.: Effects of prairie fragmentation on the nest success of breeding birds in the mid-continental United States, Conserv. Biol., 17, 587-594, 2003.

Hogan, B. W.: The plateau pika: A keystone engineer on the Tibetan Plateau, Doctoral dissertation, Arizona State University, Tempe, AZ, 2010.

Högberg, P., Nordgren, A., and Ågren, G. I.: Carbon allocation between tree root growth and root respiration in boreal pine forest, Oecologia, 132, 579-581, 2002.

Janssens, I. A., Lankreijer, H., Matteucci, G., Kowalski, A. S., Buchmann, N., Epron, D., Pilegaard, K., Kutsch, W., Longdoz, B., Grünwald, T., Montagnani, L., Dore, S., Rebmann, C., Moors, E. J., Grelle, A., Rannik, Morgenstern, K., Oltchev, S., Clement, R., Gudmundsson, J., Minerbi, S., Berbigier, P., Ibrom, A., Moncrieff, J., Aubinet, M., Bernhofer, C., Jensen, N. O., 
Vesala, T., Granier, A., Schulze, E. D., Lindroth, A., Dolman, A. J., Jarvis, P. G., Ceulemans, R., and Valentini, R.: Productivity overshadows temperature in determining soil and ecosystem respiration across european forests, Glob. Change Biol., 7, 269278, 2001.

Juszczak, R., Humphreys, E., Acosta, M., Michalak-Galczewska, M., Kayzer, D., and Olejnik, J.: Ecosystem respiration in a heterogeneous temperate peatland and its sensitivity to peat temperature and water table depth, Plant. Soil., 366, 505-520, 2013.

Kouki, J. and Löfman, S.: Forest fragmentation: processes, concepts and implications for especies, in: Key Concepts of Landscape Ecology, edited by: Dover, J. W. and Bunce, R. G. H., IALE (UK), Preston, 187-203, 1998.

Lai, C. H. and Smith, A. T.: Keystone status of plateau pikas (Ochotona curzoniae): effect of control on biodiversity of native birds, Biodivers. Conserv., 12, 1901-1912, 2003.

Lal, R.: Potential of desertification control to sequester carbon and mitigate the greenhouse effect, Climatic Change, 51, 35-72, 2001.

Le Quéré, C., Peters, G. P., Andres, R. J., Andrew, R. M., Boden, T. A., Ciais, P., Friedlingstein, P., Houghton, R. A., Marland, G., Moriarty, R., Sitch, S., Tans, P., Arneth, A., Arvanitis, A., Bakker, D. C. E., Bopp, L., Canadell, J. G., Chini, L. P., Doney, S. C., Harper, A., Harris, I., House, J. I., Jain, A. K., Jones, S. D., Kato, E., Keeling, R. F., Klein Goldewijk, K., Körtzinger, A., Koven, C., Lefèvre, N., Maignan, F., Omar, A., Ono, T., Park, G.-H., Pfeil, B., Poulter, B., Raupach, M. R., Regnier, P., Rödenbeck, C., Saito, S., Schwinger, J., Segschneider, J., Stocker, B. D., Takahashi, T., Tilbrook, B., van Heuven, S., Viovy, N., Wanninkhof, R., Wiltshire, A., and Zaehle, S.: Global carbon budget 2013, Earth Syst. Sci. Data, 6, 235-263, https://doi.org/10.5194/essd6-235-2014, 2014.

Li, W. and Zhang, Y.: Impacts of plateau pikas on soil organic matter and moisture content in alpine meadow, Acta Theriol., 26, 331$337,2006$.

Lin, X. W., Zhang, Z. H., Wang, S. P., Hu, Y. G., Xu, G. P., Luo, C. Y., Chang, X. F., Duan, J. C., Lin, Q. Y., Xu, B. R. B. Y., Wang, Y. F., Zhao, X. Q., and Xie, Z. B.: Response of ecosystem respiration to warming and grazing during the growing seasons in the alpine meadow on the Tibetan plateau, Agr. Forest Meteorol., 151, 792-802, 2011.

Lindenmayer, D. B. and Fischer, J.: Habitat fragmentation and landscape change: an ecological and conservation synthesis, Island Press, Washington, USA, 2013.

Liu, Y. S., Fan, J. W., Harris, W., Shao, Q. Q., Zhou, Y. C., Wang, N., and Li, Y.Z.: Effects of plateau pika (Ochotona curzoniae) on net ecosystem carbon exchange of grass-land in the Three Rivers Headwaters region, Qinghai-Tibet, China, Plant. Soil., 366, 491504, 2013.

Ma, Y. J., Wu, Y. N., Liu, W. L., Li, X. Y., and Lin, H. S.: Microclimate response of soil to plateau pika's disturbance in the northeast qinghai-tibet plateau, Eur. J. Soil Sci., 69, 232-244, 2018.

Martin, B. G.: The role of small ground-foraging mammals in topsoil health and biodiversity: Implications to management and restoration, Ecol. Manag. Restor., 4, 114-119, 2003.

McKey, D., Rostain, S., Iriarte, J., Glaser, B., Birk, J. J., Holst, I., and Renard, D.: Pre-Columbian agricultural landscapes, ecosystem engineers, and self-organized patchiness in Amazonia, $\mathrm{P}$. Natl. Acad. Sci. USA, 107, 7823-7828, 2010.
Nakano, T., Nemoto, M., and Shinoda, M.: Environmental controls on photosynthetic production and ecosystem respiration in semiarid grasslands of Mongolia, Agr. Forest Meteorol., 148, 14561466, 2008.

Nelson, D. W. and Sommers, L. E.: Total carbon, organic carbon and organic matter, in: Methods of soil analysis, edited by: Page, A. L., Miller, R. H., and Keeney, D. R., 2nd Edn., American Society of Agronomy, Madison, 539-577, 1982.

Nobili, M. D., Contin, M., Mondini, C., and Brookes, P. C.: Soil microbial biomass is triggered into activity by trace amounts of substrate, Soil Biol. Biochem., 33, 1163-1170, 2001.

Oberbauer, S. F., Tweedie, C. E., Welker, J. M., Fahnestock, J. T., Henry, G. H. R., Webber, P. J., Hollister, R. D., Walker, M. D., Kuchy, A., Elmore, E., and Starr, G.: Tundra $\mathrm{CO}_{2}$ fluxes in response to experimental warming across latitudinal and moisture gradients, Ecol. Monogr., 77, 221-238, 2007.

Peng, F., Quangang, Y., Xue, X., Guo, J., and Wang, T.: Effects of rodent-induced land degradation on ecosystem carbon fluxes in an alpine meadow in the Qinghai-Tibet Plateau, China, Solid Earth, 6, 303-310, https://doi.org/10.5194/se-6-303-2015, 2015.

Pielke, R. A.: Land use and climate change, Science, 310, 16251626, 2005.

Post, W. M. and Kwon, K. C.: Soil carbon sequestration and landuse change: processes and potential, Glob. Change. Biol., 6, 317327, 2000.

Qin, Y. and Yi, S.: Diurnal characteristics of ecosystem respirationof alpine meadow on the Qinghai-Tibetan plateau: Implicationsfor carbon budget estimation, Sci. World J., 2013, 9-14, 2013.

Qin, Y., Yi, S., Ren, S., Li, N., and Chen, J.: Responses of typical grasslands in a semiarid basin on the Qinghai-Tibetan plateau to climate change and disturbances, Environ. Earth. Sci., 71, 14211431, 2014.

Qin, Y., Chen, J. J., and Yi, S. H.: Plateau pikas burrowing activity accelerates ecosystem carbon emission from alpine grassland on the Qinghai-Tibetan Plateau, Ecol. Eng., 84, 287-291, 2015a.

Qin, Y., Yi, S. H., Chen, J. J., Ren, S. L., and Ding, Y. J.: Effects of gravel on soil and vegetation properties of alpine grassland on the Qinghai-Tibetan plateau, Ecol. Eng., 74, 351-355, 2015b.

Qin, Y., Yi, S., Chen, J., Ren, S., and Wang, X.: Responses of ecosystem respiration to short-term experimental warming in the alpine meadow ecosystem of a permafrost site on the qinghaitibetan plateau, Cold. Reg. Sci. Technol., 115, 77-84, $2015 \mathrm{c}$.

Qin, Y., Yi, S., Ding, Y., Xu, G., Chen, J., and Wang, Z.: Effects of small-scale patchiness of alpine grassland on ecosystem carbon and nitrogen accumulation and estimation in northeastern qinghai-tibetan plateau, Geoderma, 318, 52-63, 2018.

Raich, J. W. and Potter, C. S.: Global patterns of carbon-dioxide emissions from soils, Global Biogeochem. Cy., 9, 23-36, 1995.

Reichstein, M., Tenhunen, J. D., Roupsard, O., Ourcival, J.-M., Rambal, S., Dore, S., and Valentini, R.: Ecosystem respiration in two Mediterranean evergreen Holm oak forests: drought effects and decompsition dynamics, Funct. Ecol., 16, 27-39, 2002.

Rietkerk, M., Dekker, S. C., de Ruiter, P. C., and van de Koppel, J.: Self-organized patchiness and catastrophic shifts in ecosystems, Science, 305, 1926-1929, 2004.

Roch, L. and Jaeger, J. A.: Monitoring an ecosystem at risk: What is the degree of grassland fragmentation in the Canadian Prairies?, Environ. Monit. Assess., 186, 2505-2534, 2014. 
Saunders, D. A., Hobbs, R. J., and Margules, C. R.: Biological consequences of ecosystem fragmentation: a review, Conserv. Biol., $5,18-32,1991$.

Schimel, D. S., House, J. I., Hibbard, K. A., Bousquet, P., Ciais, P., Peylin, P., Braswell, B. H., Apps, M. J., Baker, D., Bondeau, A., Canadell, J., Churkina, G., Cramer, W., Denning, A. S., Field, C. B., Friedlingstein, P., Goodale, C., Heimann, M., Houghton, R. A., Melillo, J. M., Moore III, B., Murdiyarso, D., Noble, I., Pacala, S. W., Prentice, I. C., Raupach, M. R., Rayner, P. J., Scholes, R. J., Steffen, W. L., and Wirth, C.: Recent patterns and mechanisms of carbon exchange by terrestrial ecosystems, Nature, 414, 169-172, 2001.

Scott-Denton, L., Rosenstiel, T., and Monson, R.: Differential controls by climate and substrate over the heterotrophic and rhizospheric components of soil respiration, Glob. Change Biol., 12, 205-216, 2010.

Sikora, L. J. and Mccoy, J. L.: Attempts to determine available carbon in soils, Biol. Fert. Soils, 9, 19-24, 1990.

Smith, A. T. and Foggin, J. M.: The plateau pika (Ochotona curzoniae) is a keystone species for biodiversity on the Tibetan plateau, Anim. Conserv., 2, 235-240, 1999.

Tewary, C. K., Pandey, U., and Singh, J. S.: Soil and litter respiration rates in different microhabitats of a mixed oak-conifer forest and their control by edaphic conditions and substrate quality, Plant Soil, 65, 233-238, 1982.

Upadhyay, T. P., Sankhayan, P. L., and Solberg, B.: A review of carbon sequestration dynamics in the himalayan region as a function of land-use change and forest/soil degradation with special reference to nepal, Agr. Ecosyst. Environ., 105, 449-465, 2005.

Venegas, J. G., Winkler, T., Musch, G., Melo, M. F. V., Layfield, D., Tgavalekos, N., Fischman, A. J., Callahan, R. J., Bellani, G., and Harris, R. S.: Self-organized patchiness in asthma as a prelude to catastrophic shifts, Nature, 434, 777-782, 2005.

von Buttlar, J., Zscheischler, J., Rammig, A., Sippel, S., Reichstein, M., Knohl, A., Jung, M., Menzer, O., Arain, M. A., Buchmann, N., Cescatti, A., Gianelle, D., Kiely, G., Law, B. E., Magliulo, V., Margolis, H., McCaughey, H., Merbold, L., Migliavacca, M., Montagnani, L., Oechel, W., Pavelka, M., Peichl, M., Rambal, S., Raschi, A., Scott, R. L., Vaccari, F. P., van Gorsel, E., Varlagin, A., Wohlfahrt, G., and Mahecha, M. D.: Impacts of droughts and extreme-temperature events on gross primary production and ecosystem respiration: a systematic assessment across ecosystems and climate zones, Biogeosciences, 15, 12931318, https://doi.org/10.5194/bg-15-1293-2018, 2018.

Wang, B., Zha, T. S., Jia, X., Wu, B., Zhang, Y. Q., and Qin, S. G.: Soil moisture modifies the response of soil respiration to temperature in a desert shrub ecosystem, Biogeosciences, 11, 259-268, https://doi.org/10.5194/bg-11-259-2014, 2014

Wang, Z., Song, K., Zhang, B., Liu, D., Ren, C., Luo, L., Yang, T., Huang, N., Hu, L., Yang, H., and Liu, Z.: Shrinkage and fragmentation of grasslands in the West Songnen Plain, China, Agr. Ecosyst. Environ., 129, 315-324, 2009.

Warren, C. R. and Taranto, M. T.: Ecosystem Respiration in a Seasonally Snow-Covered Subalpine Grassland, Arct. Antarct. Alp. Res., 43, 137-146, 2011.

Wei, X. H., Li, S., and Yang, P.: Changes of soil physical and chemical property of Alpine Kobresia Meadow around plateau pika entrances in the process of related to erosion, Grassl. China, 28, 24-29, 2006 (in Chinese with English abstract).
Wilson, M. C. and Smith, A. T.: The pika and the watershed: The impact of small mammal poisoning on the ecohydrology of the Qinghai-Tibetan Plateau, Ambio, 44, 16-22, 2015.

Wu, J. K., Zhang, S. Q., Wu, H., Liu, S. W., Qin, Y., and Qin, J.: Actual Evapotranspiration in Suli Alpine Meadow in Northeastern Edge of Qinghai-Tibet Plateau, China, Adv. Meteorol., 3, 1-10, 2015.

Wuest, S. B., Williams, J. D., and Gollany, H. T.: Tillage and perennial grass effects on ponded inltration for seven semi-arid loess soils, J. Soil Water Conserv., 61, 218-223, 2006.

$\mathrm{Xu}, \mathrm{M}$. and Qi, Y.: Soil-surface $\mathrm{CO}_{2}$ efflux and its spatial and temporal variations in a young ponderosa pine plantation in northern california, Glob. Change Biol., 7, 667-677, 2010.

Yan, Y., Xin, X., Xu, X., Wang, X., Yan, R., and Murray, P. J.: Vegetation patches increase wind-blown litter accumulation in a semiarid steppe of northern China, Environ. Res. Lett., 11, 124008, https://doi.org/10.1088/1748-9326/11/12/124008, 2016.

Yang, M., Yao, T., Guo, X., Koike, T., and He, Y.: The soil moisture distribution, thawing-freezing processes and their effects on the seasonal transition on the Qinghai-Xizang (Tibetan) Platea, J. Asian Earth. Sci., 21, 457-465, 2003.

Yang, P., Lai, D. Y. F., Huang, J. F., Zhang, L. H., and Tong, C.: Temporal variations and temperature sensitivity of ecosystem respiration in three brackish marsh communities in the min river estuary, southeast china, Geoderma, 327, 138-150, 2018.

Yi, S.: Fragmap: a tool for long-term and cooperative monitoring and analysis of small-scale habitat fragmentation using an unmanned aerial vehicle, Int. J. Remote Sens., 38, 2686-2697, 2017.

Yi, S., Zhou, Z., Ren, S., Xu, M., Qin, Y., Chen, S., and Ye, B.: Effects of permafrost degradation on alpine grassland in a semiarid basin on the Qinghai-Tibetan Plateau, Environ. Res. Lett., 6, 045403, https://doi.org/10.1088/1748-9326/6/4/045403, 2011.

Yi, S., Li, N., Xiang, B., Wang, X., Ye, B., and Mcguire, A. D.: Representing the effects of alpine grassland vegetation cover on the simulation of soil thermal dynamics by ecosystem models applied to the Qinghai-Tibetan Plateau, J. Geophys. Res.-Biogeo., 118, 1186-1199, 2013.

Yi, S., Wang, X., Qin, Y., Xiang, B., and Ding, Y.: Responses of alpine grassland on Qinghai-Tibetan plateau to climate warming and permafrost degradation: a modeling perspective, Environ. Res. Lett., 9, 074014, https://doi.org/10.1088/17489326/9/7/074014, 2014.

Yi, S., Chen, J., Qin, Y., and Xu, G.: The burying and grazing effects of plateau pika on alpine grassland are small: a pilot study in a semiarid basin on the Qinghai-Tibet Plateau, Biogeosciences, 13, 6273-6284, https://doi.org/10.5194/bg-13-6273-2016, 2016.

You, Q., Xue, X., Peng, F., Dong, S., and Gao, Y.: Surface water and heat exchange comparison between alpine meadow and bare land in a permafrost region of the Tibetan Plateau, Agr. Forest Meteorol., 232, 48-65, 2017.

Yuste, J. C., Janssens, I. A., Carrara, A., Meiresonne, L., and Ceulemans, R.: Interactive effects of temperature and precipitation on soil respiration in a temperate maritime pine forest, Tree Physiol., 23, 1263-1270, 2003.

Zhang, T., Wang, G., Yang, Y., Mao, T., and Chen, X.: Grassland types and season-dependent response of ecosystem respiration to experimental warming in a permafrost region in the tibetan plateau, Agr. Forest. Meteorol., 247, 271-279, 2017. 
Zhang, Y., Dong, S., Gao, Q., Liu, S., Liang, Y., and Cao, X.: Responses of alpine vegetation and soils to the disturbance of plateau pika (Ochotona curzoniae) at burrow level on the Qinghai-Tibetan Plateau of China, Ecol. Eng., 88, 232-236, 2016.

Zhang, Z. and Dong, Z.: Characteristics of aeolian sediment transport over different land surfaces in northern China, Soil Till. Res., 143, 106-115, 2014.
Zhou, H., Zhou, L., Zhao, X., Yan, Z., Liu, W., and Shi, Y.: The degraded process and integrated treatment of "black soil beach" type degraded grassland in the source regions of Yangtze and Yellow Rivers, China J. Ecol., 22, 51-55, 2003 (in Chinese with English abstract). 